\title{
Update on prevention of diabetic foot ulcer
}

\author{
Cesare Miranda ${ }^{1}$, Roberto Da Ros ${ }^{2}$, Raffaele Marfella
}

${ }^{1}$ Clinic of Endocrinology and Metabolism Diseases, Department of Internal Medicine, Azienda Sanitaria Friuli, Pordenone, Italy

${ }^{2}$ Clinic of Diabetology, Department of Internal Medicine, Azienda Sanitaria

Universitaria Giuliana Isontina, Monfalcone, Italy

3Department of Advanced Medical and Surgical Sciences (DAMSS),

University of Campania 'Luigi Vanvitelli', Naples, Italy

Submitted: 29 April 2021

Accepted: 28 June 2021

Arch Med Sci Atheroscler Dis 2021; 6: e123-e131

DOI: https://doi.org/10.5114/amsad.2021.107817

Copyright @ 2021 Termedia \& Banach

\section{Abstract}

The diabetic foot ulcer is the most important reason for non-traumatic limb amputation. Based on recent data, it has been estimated that up to $34 \%$ of type 2 diabetes patients may develop diabetic foot ulcers once in their lifetime. Risk factors for developing foot ulcers are distal sensorimotor peripheral neuropathy, peripheral arterial disease, previous ulcers, and/or amputations. Understanding the factors that place patients with diabetes mellitus at high ulceration risk and the early treatment of risk factors, and continuous education of the patient (and/or caregivers) are essential for the prevention and management of diabetic foot complications. Implementing strategies to prevent these complications is a key aspect of diabetes care, but the most effective strategy in prevention has to be investigated. More evidence from well-designed studies is needed on this topic.

Key words: prevention, amputation, peripheral neuropathy, diabetic foot ulcer, peripheral arterial disease.

\section{Introduction}

Diabetes mellitus represents a real pandemic. According to the International Diabetes Federation [1] by 2045, approximately 700 million people will live with diabetes. In Italy [2], more than 3 million people are diagnosed with diabetes, $5.3 \%$ of the total population, and about another million people have the condition but are not aware of it. It is estimated that the incidence of lesions is around $2 \%$ per year, while the lifetime incidence is between 19\% and 34\% [3].

The risk for ulcer recurrence is high, with recurrence rates of $40 \%$ in the first year and $65 \%$ in the first 3 years after healing [3]. The burden of diabetic foot disease is ranked in the top 10 of all medical conditions [4]. Direct and indirect costs for such a debilitating disease are very high [5-7].

\section{Etiology and pathway to ulceration}

In people with diabetes mellitus, the risk factors for developing ulcers are distal peripheral neuropathy, peripheral arterial disease, repeated trauma, previous ulcers, and/or amputation. The most affected are male subjects, with a longer duration of illness and low socio-economic level [8-10]. 
About $50 \%$ of people with type 2 diabetes have neuropathy and feet at risk. Neuropathy is defined as "the presence of signs and/or symptoms of peripheral nerve dysfunction in people with diabetes in the absence of other possible causes other than diabetes [11].

There are several forms of peripheral neuropathy, but the main forms associated with the diabetic foot are distal-symmetric sensorimotor neuropathy and autonomic neuropathy. Neuropathy causes a reduction in sensitivity up to complete loss, so even small traumas (improper nail cutting, inadequate footwear, burns) can cause an ulcer. The neuropathic foot has a deformed appearance, the skin appears dry and is warm to the touch with hyperkeratosis in the plantar surface, the veins are turgid, and arterial pulses are present. Autonomic neuropathy causes alterations in the control of capillary microcirculation, with shunts opening between arterioles and veins and turgidity of the veins of the foot with a hot but dry skin surface with a tendency to develop fissures, especially at the heels. Loss of sensitivity, deformity of the foot, and limited joint mobility cause biomechanical anomalies of foot loading, so thickened skin (callus) is formed, which is responsible for a further increase in the load and development of a subcutaneous hematoma, which by autolysis causes the formation of a severe or serum ematic cavity, which opens to the outside and therefore leads to the formation of an ulcer.

The neuropathic ulcer is localized in areas of high plantar pressure, generally on the sole at the level of the metatarsal heads, on the plantar surface of the toes, the perilesional skin is hyperkeratotic (sometimes the hyperkeratosis overhangs the ulcer), the edges are high and jagged, the bottom appears bright red, tending to granulation and with a strong tendency to bleeding, and in most cases pain is absent.

Peripheral arterial disease (PAD) is defined as any atherosclerotic arterial occlusive disease below the level of the inguinal ligament resulting in a reduction in blood flow to the lower extremity [12].

In patients with diabetic foot ulcers, approximately $50 \%$ show signs of peripheral arterial disease [13]. Compared with subjects with PAD and no diabetes, subjects with diabetes and PAD are usually younger, have a higher body mass index (BMI), and have more cardiovascular comorbidities [14].

Other clinical peculiarities of PAD in subjects with diabetes are its rapid progression and distal prevalence. Indeed, PAD more frequently affects below-the-knee vessels such as the tibial and peroneal arteries and is symmetric and multi-segmental, and the collateral vessels can also be affected by stenosis $[15,16]$ while the typical histopathological characteristic is the higher incidence of vascular calcifications $[17,18]$.

In subjects with diabetes, PAD is often paucior asymptomatic [19], probably due to the concomitant presence of neuropathy that may mask symptoms of PAD and reduces lower limbs' sensitivity [20]

The ischemic foot objectively appears pale, cold to the touch, and the distal pulses are reduced or absent, the skin is dry, dystrophic, hair is absent, and there can be fissures in the heels.

Usually, the ischemic ulcer is localized on the toes, internal and external margins, heel, interdigital spaces, has a necrotic aspect or presents areas of necrosis, the edges are flat and well defined, the perilesional tissue is ischemic (absence of perilesional hyperkeratosis), and the background is usually pale or necrotic with little tendency to bleed. In contrast, perilesional skin is pale and atrophic, and pain is present.

Neuropathy and PAD often co-exist and may lead to neuroischemic ulceration, and symptoms may be absent, despite severe peripheral ischemia. The combination of two or more of the above risk factors commonly results in ulceration. The majority of injuries to the diabetic foot are caused by trauma in the presence of neuropathy and/or PAD: repetitive stress [3], thermal trauma (hot water bags, high-temperature footbaths), chemical trauma (inappropriate use of over-thecounter corn treatments) [21].

The management and prevention of diabetic foot ulcer takes a holistic approach and includes 1) standard care (glycemic control, management of peripheral arterial disease and cardiovascular risk factors), 2) identifying the at-risk foot, 3) regularly inspecting and examining the at-risk foot, 4) educating the patient, family and healthcare providers, 5) ensuring routine wearing of appropriate footwear, 6) treating risk factors for ulceration, 7) integrated foot care.

\section{Standards of care}

\section{Glycemic control}

Glycemic control is the proven primary prevention of microvascular complications [22]. The UK Prospective Diabetes Study (UKPDS) showed that intensive glycemic control reduced microvascular complications, including neuropathy, compared with standard regimens [23], while a long follow-up ( $\leq 20$ years) is necessary to obtain a beneficial effect on macrovascular complications [24]. According to current guidelines, glycated hemoglobin $\left(\mathrm{HbA}_{1 \mathrm{c}}\right)$ goals should be individualized, with more stringent goals $(6.5 \%(48 \mathrm{mmol} / \mathrm{mol}))$ in younger people with a short duration of diabetes mellitus and no evidence of cardiovascular disease, if achieved without significant hypoglycemia. 
Less stringent $\mathrm{HbA}_{1 \mathrm{c}}$ objectives ( $\leq 8 \%(64 \mathrm{mmol} /$ $\mathrm{mol})$ or $\leq 9 \%(75 \mathrm{mmol} / \mathrm{mol}))$ may be appropriate for elderly persons with long-standing diabetes and limited life expectancy and frailty with multiple comorbidities, including hypoglycemic episodes $[25,26]$.

Metformin is the preferred initial pharmacologic agent for the treatment of type 2 diabetes. Among patients with type 2 diabetes mellitus (T2DM) who have established atherosclerotic cardiovascular disease or indicators of high risk, established kidney disease, or heart failure, a sodium-glucose cotransporter 2 inhibitor or glucagon-like peptide 1 receptor agonist with demonstrated cardiovascular disease benefit is recommended $[25,26]$.

Instead insulin therapy is indicated if there is evidence of weight loss, if symptoms of hyperglycemia are present, or when $A_{1 c}$ levels (10\% (86 $\mathrm{mmol} / \mathrm{mol})$ ) or blood glucose levels $(\geq 300 \mathrm{mg} / \mathrm{dl}$ $(16.7 \mathrm{mmol} / \mathrm{l}))$ are very high [25]. Only a retrospective cohort study [27] has shown that insulin glargine therapy compared with neutral protamine Hagedorn (NPH) insulin significantly reduces the risk of diabetic foot ulcer.

\section{Management of PAD}

Diabetic people with PAD have a much higher risk of cardiovascular events than patients who have already had a myocardial infarction or stroke [28]. Hence, they should receive prompt and aggressive cardiovascular risk, including lifestyle changes and optimization of glycemic, lipid, and blood pressure control $[15,16]$.

Lifestyle changes include smoking cessation, regular exercise, a healthy diet, and weight management. For glycemic control in patients with diabetes mellitus and PAD, current guidelines recommend sodium-glucose cotransporter 2 inhibitor or glucagon-like peptide 1 receptor agonist with demonstrated cardiovascular disease benefit independent of $A_{1 c}[25,26]$.

There is concern that SGLT-2 inhibitors may raise the risk of peripheral artery disease and lower extremity amputation. Two clinical trials, CANVAS and CANVAS-R, demonstrated an approximate doubling of the risk of minor amputations with canagliflozin compared to placebo (6.3 vs. 3.4 participants with amputations per 1000 patient-years) [29]. For this reason, in May 2017, the FDA issued a Drug Safety Communication regarding an increased risk of foot and leg amputations using canagliflozin [30]. However, after reviewing new data from three clinical trials, in August 2020, the FDA removed the boxed warning about amputation risk from the diabetes medicine canagliflozin [31].

Moreover, a sub-analysis of EMPAREG-OUTCOME showed that in patients with T2DM and PAD, em- pagliflozin reduced mortality, hospitalization for heart failure and progression of renal disease without increasing the risk of lower extremity amputation [32]. A meta-analysis showed that empagliflozin or dapagliflozin does not increase the risk of either peripheral artery disease or lower limb amputations [33].

A post hoc analysis of data from the LEADER trial demonstrated that treatment with liraglutide did not increase the risk of diabetic foot ulcers and reduced amputations compared with placebo [34]. The mechanisms by which liraglutide reduced the risk of ulcer are not known.

For lipid control, low-density lipoprotein (LDL) targets $<1.4 \mathrm{mmol} / \mathrm{mol}(<55 \mathrm{mg} / \mathrm{dl})$ or a $50 \%$ reduction in LDL cholesterol are recommended [26]. High-dose statins, when tolerated, are the treatment of choice.

Other drugs such as ezetimibe and PCKS9 inhibitors should be considered when goals are not met $[28,35,36]$. Evolocumab, a PCKS9 inhibitor, added to the statin, has been shown to significantly reduce the risk of major cardiovascular events, as well as reducing the risk of major adverse limb events such as acute limb ischemia, major amputation, or urgent peripheral revascularization for ischemia in patients with and without PAD [28].

A target $<140 / 90 \mathrm{~mm} \mathrm{Hg}$ is recommended for blood pressure control, and angiotensin converting enzyme inhibitors (ACEls) or angiotensin-receptor blockers (ARBs) should be considered firstline therapy $[37,38]$.

In subjects with diabetes and symptomatic PAD, antiplatelet therapy is recommended [26].

Low-dose aspirin (ASA) (75-160 mg) is effective and safe during related complications such as gastrointestinal bleeding [39].

Aspirin (ASA) or clopidogrel is indicated for secondary prevention in patients with PAD and/or other cardiovascular diseases but some data encourage the use of clopidogrel over aspirin in patients with diabetes and PAD. In the CAPRIE trial, in which $20 \%$ of participants were diabetic, there was a reduction in PAD-related events in the clopidogrel 75 $\mathrm{mg}$ arm compared to the aspirin $325 \mathrm{mg}$ arm [40].

In subjects with diabetes who undergo lower limb revascularization, dual antiplatelet therapy (ASA + clopidogrel or ticlopidine) is recommended for at least 1 month after the endovascular procedure; after 1 month, ASA or clopidogrel should be continued lifelong [41].

The effect of a low-dose antithrombotic therapy with the new oral anticoagulants in combination with ASA has been investigated. In the Compass study, in the subgroup of PAD patients with diabetes mellitus (44\%), the combination of rivaroxaban $2.5 \mathrm{mg}$ b.i.d. with aspirin $100 \mathrm{mg}$ reduced major adverse limb events including amputation $(\mathrm{HR}=0.54 ; p=0.0037)[42]$. 
Some drugs (cilostazol, naftidrofuryl) have been shown to increase walking distance in subjects with intermittent claudication, with no clear benefit from cardiovascular effects [38].

Furthermore, cilostazol is contraindicated in patients with clinically manifest heart failure, unstable angina pectoris and $\mathrm{MI}$, or coronary intervention within 6 months, as well as severe tachyarrhythmia [43].

\section{Strategy for prevention of diabetic foot ulcer}

Prevention of first and recurrent foot ulcers in subjects with diabetes who are at risk for ulceration is essential to reduce the risk of amputation.

In the International Working Group on the Diabetic Foot (IWGDF) Guidelines 2019 [44], five key elements underpin prevention of foot problems: 1) identifying the at-risk foot; 2) regularly inspecting and examining the at-risk foot; 3) educating the patient, family and healthcare providers; 4) ensuring routine wearing of appropriate footwear; 5) treating risk factors for ulceration.

Several studies have demonstrated that introducing a multidisciplinary team for managing the diabetic foot headed by the endocrinology department is associated with a reduction in the frequency of major amputations in patients with diabetes [45-47].

\section{Identifying the at-risk foot}

The absence of symptoms does not mean that the feet are healthy; the patient could have a asymptomatic neuropathy, peripheral vascular diseases, or even an ulcer without evidence. Diabetic foot screening, conducted according to guidelines developed by the International Diabetic Foot Study Group, includes a detailed medical history, physical examination of the feet, screening for the loss of protective sensitivity (LOPS) and peripheral arterial disease (PAD) [12].

The screening of peripheral neuropathy aimed at identifying the loss of protective sensitivity (LOPS) can be conducted with a 10-gram Semmes Weinstein monofilament [48] or with the Ipswich Touch Test if a 10-gram monofilament is unavailable [49] and using a structured scoring system such as the Diabetic Neuropathy Index (DNI) [50], which includes inspection of the foot (detection of ulcers, dry skin, callosities, deformities, infections), examination of Achilles tendon reflexes and evaluation of the threshold of vibratory sensation with a tuning fork or biothesiometer/neurothesiometer applied to the big toe. Screening for PAD includes taking a cardiovascular history, palpating for foot pulses, obtaining pedal Doppler arterial waveforms, and blood pressure measure- ments [12]. In people with diabetic foot ulcers, it is recommended to evaluate pedal Doppler arterial waveforms in combination with systolic ankle pressure and systolic ankle-brachial index (ABI) or toe systolic pressure and toe brachial index (TBI) measurement [12].

According to the criteria proposed by the American Diabetes Association [15], the severity of the peripheral arterial disease is studied as follows: $A B I>1.30$ high probability of medial arterial calcification, $A B I$ in the range $0.91-1.30$ normal, $A B I$ in the range $0.70-0.90$ mild arteriopathy, $A B I$ in the range $0.40-0.69$ moderate arteriopathy, $A B \mid$ $<0.40$ severe arteriopathy.

Although evidence for a screening interval is non-existent, the ADA recommends annual screening for a person with diabetes in whom LOPS or PAD has not yet been identified.

\section{Regularly inspecting and examining the at-risk foot}

\section{IWGDF Risk Stratification}

According to the screening results, patients can be stratified according to their risk for foot ulceration [44]. Category 0 is characterized by the absence of LOP and PAD, and it is very low risk for ulceration. These persons require only annual screening. Category 1 is characterized by LOPS or PAD but in the absence of additional risk factors, and it is at low risk for ulceration. These persons require screening once every 6-12 months. Category 2 is characterized by a combination of risk factors, and it is a moderate risk. These persons require screening every 3-6 months. Category 3 includes persons at high risk of ulceration because they have LOPS or PAD associated with the history of a foot ulcer or a lower-extremity amputation (minor or major) or end-stage renal disease. These persons require screening every 1-3 months.

\section{Educating the patient, family,} and healthcare providers

Therapeutic education, provided in a structured, organized, and repeated way, plays an important role in preventing foot problems. Therapeutic education has been defined by the WHO as a permanent process, integrated with care and centered on the patient, which aims to help patients and their families understand the disease and the treatment, collaborate with health personnel, live more healthily and maintain or improve their quality of life [51]. The goal of therapeutic education is to improve patients' knowledge of foot care, awareness, and self-management, and improve motivation and skills to facilitate adherence to appropriate behaviors [52, 53]. People with diabetes should learn to recognize potential 
foot problems and be aware of the steps to take when necessary.

Patients at risk should understand the relationship between glycemic control, lifestyle and foot problems [54]. For subjects with neuropathy, daily foot monitoring is essential, as well as adequate foot care, including nail and skin care, and the selection of appropriate footwear.

Shoes are one of the most important elements in the development of lesions, in particular in the presence of internal seams or a shape not corresponding to the foot. Patients should be advised to use new shoes gradually to minimize blistering and ulcers. The educational intervention program requires the design and implementation of appropriate assessment tools that can assess the skills and performance of the subjects studied. The practical demonstration to the patients of some abilities such as cutting the nails or the treatment of calluses should always be done. The educational program must provide several educational sessions over time, use various methods (e.g., individual or group sessions) and different intervals (for example, single or weekly meetings). During the educational treatment, it is essential to assess whether the person with diabetes or a family caregiver has understood the messages and has sufficient self-care skills. The educator must demonstrate skills and knowledge, and be able to assess the effectiveness of education. A team member should provide education in various sessions over time, preferably using different methods. Also, health professionals providing the instructions should receive periodic training to improve their skills in caring for patients at high risk of foot ulceration [55].

The literature data on the effectiveness of therapeutic education in injury prevention are unfortunately scarce. The last Cochrane review [56] showed that only 5 of the 12 randomized controlled clinical studies reported the effects of therapeutic education on primary endpoints. One study [57] showed after one year of follow-up that the incidence of lesions and amputations was lower in the group of patients who received an hour of group education from a podiatrist than in the group of patients who only received routine information on the diabetic foot. However, a similar study conducted by Lincoln [58], but with less risk of bias than the work of Malone [57], did not confirm these results.

Unfortunately, for every euro spent on injury prevention, as many as 10 euros are spent on wound healing [59].

Van Netten [10], confirming what had already been demonstrated by the Cochrane review [56], reiterated in his review that the two randomized controlled clinical trials and the three uncontrolled studies do not robustly support the efficacy of a single session of therapeutic education in injury prevention.

In a randomized controlled trial (RCT), Monami et al. [60] demonstrated in 121 patients that a brief 2-hour focus group effectively prevents diabetic foot ulcers in high-risk patients. In this study, patients were randomized in a $1: 1$ ratio either to the intervention or to the control group. The intervention was a two-hour program provided to groups of 5-7 patients, including a 30-minute face-to-face lesson on risk factors for foot ulcers and a 90-minute interactive session with practical exercises on behaviors for reducing risk. The intervention involved a physician (for $15 \mathrm{~min}$ ) and a nurse (for $105 \mathrm{~min}$ ). At randomization, the PIN (Patient Interpretation of Neuropathy) questionnaire was administered to the patients, exploring patients' knowledge about signs and symptoms of neuropathy and risk factors for foot ulcer onset. Patients randomized to the control group were supplied with a brief leaflet with some recommendations for ulcer prevention. During the 6-month follow-up, 6 patients in the control group developed ulcers ( $10 \%$ vs. $0 \%, p<0.012)$.

The questionnaire score improved significantly after the intervention (20 vs. 23, $p<0.001$ ). There were two main limitations of this study. First, the trial was conducted in a single center, performed by highly trained health professionals working in a diabetic foot clinic; the reproducibility of the program should be verified in different settings. Second, the therapeutic effects of patients' education tend to fade with time [61]. The durability of beneficial effects needs to be formally tested in a study with a longer follow-up. Several studies have shown that a structured therapeutic patient education (TPE) can bring a significant improvement in several clinical, lifestyle, and psychosocial outcomes in people who have diabetes [62-64], while there are a few data regarding the potential direct and indirect role that a structured TPE may have in the prevention of diabetic complications $[65,66]$. The best setup for patient education to be beneficial in prevention may yet have to be investigated because the education of the patient for the prevention of foot ulcers receives poor attention and is a neglected opportunity [67].

\section{Ensuring routine wearing of appropriate footwear}

People at moderate or high risk for foot ulceration (IWGDF risk 2-3) have often lost the sense of pain and may not adequately judge the fit of their footwear or the level of pressure on their foot. Their footwear must be appropriate for people at increased risk for ulceration, with adequate length, width, and depth [68].

In persons with foot deformity or pre-ulcerative signs, custom-made footwear, custom-made 
insoles, or toe orthoses may be used to reduce plantar pressure, while for people with a healed plantar foot ulcer (IWGDF risk 3), therapeutic footwear needs to reduce plantar pressure in high-risk areas. Two RCTs with very low risk of bias have shown a reduction in ulcer risk with custom-made orthopedic footwear [69] or custom-made insoles [70] in persons with diabetes and a previous plantar ulcer (IWGDF risk 3).

\section{Treating risk factors for ulceration}

Pre-ulcerative signs on feet (callus, blisters, fissures or hemorrhages, ingrown or thickened toenails, and fungal infections) require appropriate treatment by an appropriately trained foot care professional. Preventative surgery [71, 72], such as flexor tenotomy, Achilles tendon lengthening, joint arthroplasty, single or pan metatarsal head resection, metatarsophalangeal joint arthroplasty or osteotomy, may reduce the risk of a recurrent foot ulcer. However, after a full evaluation of nonsurgical treatment options, it should only be considered by an appropriately trained foot care professional [73-76].

\section{Integrated foot care}

Integrated foot care is a combination of key elements that underpin the prevention of foot problems, and it is defined as an intervention that at a minimum integrates regular foot care and examination by an adequately trained pro- fessional, structured education, and adequate footwear [44].

Integrated foot care may also integrate foot self-management and, as necessary, reconstructive foot surgery. Several studies have shown that the home monitoring of foot skin temperatures could effectively reduce the incidence of recurrent plantar ulcers [77, 78].

Foot surgery can reduce the risk of recurrent ulcers, both plantar and non-plantar, in selected patients who have not responded to nonsurgical treatment. No controlled or non-controlled studies have included all potential components of integrated foot care. Two reviews $[5,53]$ have investigated the effect sizes of the various components of integrated foot care and have shown that the largest effect sizes in ulcer prevention can be found for self-management and surgical interventions and a complete integrated approach should include these as well.

\section{Conclusions}

The foot ulcer is a complication of diabetes that can be prevented. Understanding the factors that place patients with diabetes mellitus at high risk of ulceration, together with tight glycemic control and the early treatment of risk factors and continuous education of the patient and caregivers, is essential for the prevention and management of diabetic foot complications.

This paper described and analyzed the available evidence and current clinical practice recommendations on this topic.

Table I. Flow diagram for prevention of diabetic foot ulcers

\begin{tabular}{|c|c|c|c|}
\hline \multicolumn{4}{|c|}{ Multidisciplinary approach } \\
\hline Glycemic control & Management of PAD & $\begin{array}{l}\text { Identifying the at-risk } \\
\text { foot }\end{array}$ & $\begin{array}{l}\text { Regularly inspecting and } \\
\text { examining the at-risk foot }\end{array}$ \\
\hline $\begin{array}{l}\mathrm{HbA}_{1 \mathrm{c}} \text { target : } \\
\text { - For most adults is } \\
<7.0 \% \text { (< } 53 \mathrm{~mol} / \mathrm{mol}) \\
\text { - For young patients is } \\
<6.5 \% \text { ( } 48 \mathrm{~mol} / \mathrm{mol}) \\
\text { if this can be achieved } \\
\text { without significant } \\
\text { hypoglycemia or other } \\
\text { adverse effects of } \\
\text { treatment } \\
\text { - For elderly patients is } \\
<8 \% \text { ( } 64 \mathrm{mmol} / \mathrm{mol}) \text { or } \\
\leq 9 \% \text { ( } 75 \mathrm{mmol} / \mathrm{mol}) \\
\text { may be adequate }\end{array}$ & $\begin{array}{l}\text { Lifestyle changes: } \\
\text { - Smoking cessation } \\
\text { - Regular exercise } \\
\text { - Healthy diet } \\
\text { - Weight management } \\
\text { Medical therapy: } \\
\text { - Lipid control: } \\
\text { LDL < } 55 \text { mg/dl } \\
\text { - Hypertension control } \\
\text { - SGLT2 inhibitor or GLP-1 } \\
\text { RA with demonstrated } \\
\text { CVD benefit } \\
\text { Antithrombotic therapy: } \\
\text { - Antiplatelet therapy in } \\
\text { symptomatic PAD }\end{array}$ & $\begin{array}{l}\text { - Medical history } \\
\text { - Objective examination } \\
\text { of the feet } \\
\text { - Screening of peripheral } \\
\text { neuropathy and PAD }\end{array}$ & $\begin{array}{l}\text { - IWGDF Risk } \\
\text { Stratification Follow-up }\end{array}$ \\
\hline $\begin{array}{c}\text { Educating the patient, } \\
\text { family and healthcare } \\
\text { providers }\end{array}$ & $\begin{array}{l}\text { Ensuring routine wearing } \\
\text { of appropriate footwear }\end{array}$ & $\begin{array}{c}\text { Treating risk factors for } \\
\text { ulceration }\end{array}$ & Integrated foot care \\
\hline $\begin{array}{l}\text { - Design and } \\
\text { implementation of } \\
\text { appropriate assessment } \\
\text { tools }\end{array}$ & $\begin{array}{l}\text { - Footwear fits } \\
\text { - Custom-made } \\
\text { orthopedic footwear } \\
\text { - Custom-made insoles }\end{array}$ & $\begin{array}{l}\text { - Pre-ulcerative lesion } \\
\text { treatment } \\
\text { - Preventative surgery }\end{array}$ & $\begin{array}{l}\text { - Combination of key } \\
\text { elements that underpin } \\
\text { prevention of foot } \\
\text { problems }\end{array}$ \\
\hline
\end{tabular}


The management of diabetic foot prevention ulcers takes a holistic approach to the patient (Table I), but the best setup for diabetic ulcers may yet have to be investigated. Diabetic foot ulceration poses a heavy burden on the patient and the healthcare system, but still ulcer prevention is a neglected opportunity [79].

In 2015, authors of guidelines from the International Working Group on the Diabetic Foot (IWGDF) [80] underlined that a shift in priority in care and research in diabetic foot disease was needed, while other experts argued that more evidence from properly designed studies on this topic is necessary [81].

However, after 4 years, diabetic foot ulcer prevention is still neglected in research. Between 2015 and 2019, 83 RCTs on diabetic foot were published, but only two RCTs were conducted on prevention while 72 were on ulcer healing [82].

We hope for more resources and investments in diabetic foot ulcer prevention in research and clinical practice.

\section{Conflict of interest}

The authors declare no conflict of interest.

\section{References}

1. International Diabetes Federation. IDF Diabetes Atlas, Nine Edition 2019. Available at: http://www.diabetesatlas.org. Accessed at : 13.12.2020.

2. ISTAT 2017. Available at: http://www.epicentro.iss.it/ igea.it/. Accessed at: 13.12.2020.

3. Armstrong DG, Boulton AJM, Bus SA. Diabetic foot ulcers and their recurrence. N Engl J Med 2017; 376: 2367-75.

4. Lazzarini PA, Pacella RE, Armstrong DG, van Netten JJ. Diabetes-related lower-extremity complications are a leading cause of the global burden of disability. Diabet Med 2018 May 23. doi: 10.1111/dme.13680.

5. Prompers L, Huijberts M, Schaper N, et al. Resource utilisation and costs associated with the treatment of diabetic foot ulcers. Prospective data from the Eurodiale Study. Diabetologia 2008; 51: 1826-34.

6. Kerr M, Barron E, Chadwick P, et al. The cost of diabetic foot ulcers and amputations to the National Health Service in England. Diabet Med 2019; 36: 995-1002.

7. American Diabetes Association. Economic Costs of Diabetes in the U.S. in 2017. Diabetes Care 2018; 41: 917-28.

8. Boyko EJ, Ahroni JH, Stensel V, Forsberg RC, Davignon DR, Smith DG. A prospective study of risk factors for diabetic foot ulcer. The Seattle Diabetic Foot Study. Diabetes Care 1999; 22: 1036-42.

9. Boulton AJ, Armstrong DG, Albert SF, et al. American Diabetes Association; American Association of Clinical Endocrinologists. Comprehensive foot examination and risk assessment: a report of the task force of the foot care interest group of the American Diabetes Association, with endorsement by the American Association of Clinical Endocrinologists. Diabetes Care 2008; 31: 1679-85.

10. van Netten JJ, Price PE, Lavery LA, et al.; International Working Group on the Diabetic Foot. Prevention of foot ulcers in the at-risk patient with diabetes: a systematic review. Diabetes Metab Res Rev 2016; 32 Suppl 1: 84-98.

11. Consensus statement: Report and recommendations of the San Antonio conference on diabetic neuropathy. American Diabetes Association American Academy of Neurology. Diabetes Care 1988; 11: 592-7.

12. Hinchliffe RJ, Forsythe RO, Apelqvist J, et al.; International Working Group on the Diabetic Foot (IWGDF). Guidelines on diagnosis, prognosis, and management of peripheral artery disease in patients with foot ulcers and diabetes (IWGDF 2019 update). Diabetes Metab Res Rev 2020; 36 Suppl 1: e3276.

13. Prompers L, Huijberts M, Apelqvist J, et al. High prevalence of ischaemia, infection and serious comorbidity in patients with diabetic foot disease in Europe. Baseline results from the Eurodiale study. Diabetologia 2007; 50: 18-25.

14. Brevetti G, Laurenzano E, Giugliano G, et al. Metabolic syndrome and cardiovascular risk prediction in peripheral arterial disease. Nutr Metab Cardiovasc Dis 2010; 20: 676-82.

15. American Diabetes Association. Peripheral arterial disease in people with diabetes. Diabetes Care 2003; 26: 3333-41.

16. Jude EB, Oyibo SO, Chalmers N, Boulton AJ. Peripheral arterial disease in diabetic and nondiabetic patients: a comparison of severity and outcome. Diabetes Care 2001; 24: 1433-7.

17. Andresen JL, Rasmussen LM, Ledet T. Diabetic macroangiopathy and atherosclerosis. Diabetes 1996; 45 Suppl 3: S91-4.

18. Shanahan CM, Cary NR, Salisbury JR, Proudfoot D, Weissberg PL, Edmonds ME. Medial localization of mineralization-regulating proteins in association with Mönckeberg's sclerosis: evidence for smooth muscle cell-mediated vascular calcification. Circulation 1999; 100: 2168-76.

19. Dolan NC, Liu K, Criqui MH, et al. Peripheral artery disease, diabetes, and reduced lower extremity functioning. Diabetes Care 2002; 25: 113-20.

20. Criqui MH, Fronek A, Barrett-Connor E, Klauber MR, Gabriel S, Goodman D. The prevalence of peripheral arterial disease in a defined population. Circulation 1985; 71: 510-5.

21. Boulton AJM. The pathway to ulceration. In: The Foot in Diabetes. $5^{\text {th }}$ edn. Boulton AJM, Rayman G, Wukich DK (eds). John Wiley \& Sons, Chichester UK 2019.

22. Hemmingsen B, Lund SS, Gluud C, et al. Targeting intensive glycaemic control versus targeting conventional glycaemic control for type 2 diabetes mellitus. Cochrane Database Syst Rev 2013; 11: CD008143. Update in: Cochrane Database Syst Rev 2015; 7: CD008143.

23. Effect of intensive blood-glucose control with Metformin on complications in overweight patients with type 2 diabetes (UKPDS 34). UK Prospective Diabetes Study (UKPDS) Group. Lancet 1998; 352: 854-65.

24. Holman RR, Paul SK, Bethel MA, Matthews DR, Neil HA. 10-year follow-up of intensive glucose control in type 2 diabetes. N Engl J Med 2008; 359: 1577-89.

25. American Diabetes Association. 9. Pharmacologic Approaches to Glycemic Treatment: Standards of Medical Care in Diabetes-2021. Diabetes Care 2021; 44 (Suppl 1): S111-24.

26. Cosentino F, Grant PJ, Aboyans V, et al.; ESC Scientific Document Group. 2019 ESC Guidelines on diabetes, pre-diabetes, and cardiovascular diseases developed in collaboration with the EASD. Eur Heart J 2020; 41: 255-323. 
27. Kostev K, Dippel FW, Rockel T, Siegmund T. Risk of diabetic foot ulceration during treatment with insulin glargine and NPH insulin. J Wound Care 2012; 21: 4834, 486-9.

28. Bonaca MP, Nault P, Giugliano RP, et al. Low-density lipoprotein cholesterol lowering with evolocumab and outcomes in patients with peripheral artery disease: insights from the FOURIER Trial (Further Cardiovascular Outcomes Research With PCSK9 Inhibition in Subjects With Elevated Risk). Circulation 2018; 137: 338-50.

29. Neal B, Perkovic V, Mahaffey KW, et al.; CANVAS Program Collaborative Group. Canagliflozin and cardiovascular and renal events in type 2 diabetes. $\mathrm{N}$ Engl J Med 2017; 377: 644-57.

30. US Food and Drug Administration. FDA drug safety communication: FDA confirms increased risk of leg and foot amputations with the diabetes medicine canagliflozin (Invokana, Invokamet, Invokamet XR). https://www.fda. gov/downloads/Drugs/DrugSafety/UCM558427.pdf. Updated May 16, 2017. Accessed June 14, 2020.

31. U.S. Food and Drug Administration. FDA drug safety communication: FDA removes Boxed Warning about risk of leg and foot amputations for the diabetes medicine canagliflozin (Invokana, Invokamet, Invokamet XR) Based on our review of new clinical trial data. [article online], 8-26 2020. https://www.fda.gov/DrugsSaefty/ ucm505860.htm. Updated August 26.2020. Accessed 21 October 2020.

32. Verma S, Mazer CD, Al-Omran M, et al. Cardiovascular outcomes and safety of empagliflozin in patients with type 2 diabetes mellitus and peripheral artery disease: a subanalysis of EMPA-REG OUTCOME. Circulation 2018; 137: 405-7.

33. Dicembrini I, Tomberli B, Nreu B, et al. Peripheral artery disease and amputations with sodium-glucose co-transporter-2 (SGLT-2) inhibitors: a meta-analysis of randomized controlled trials. Diabetes Res Clin Pract 2019; 153: 138-44.

34. Dhatariya K, Bain SC, Buse JB, et al.; LEADER Publication Committee on behalf of the LEADER Trial Investigators. The impact of liraglutide on diabetes-related foot ulceration and associated complications in patients with type 2 diabetes at high risk for cardiovascular events: results from the LEADER trial. Diabetes Care 2018; 41: 2229-35.

35. Cannon CP, Blazing MA, Giugliano RP, et al.; IMPROVE-IT Investigators. Ezetimibe added to statin therapy after acute coronary syndromes. N Engl J Med 2015; 372: 2387-97.

36. Giugliano RP, Cannon CP, Blazing MA, et al.; IMPROVE-IT (Improved Reduction of Outcomes: Vytorin Efficacy International Trial) Investigators. Benefit of adding ezetimibe to statin therapy on cardiovascular outcomes and safety in patients with versus without diabetes mellitus: results from IMPROVE-IT (Improved Reduction of Outcomes: Vytorin Efficacy International Trial). Circulation 2018; 137: 1571-82.

37. Gerhard-Herman MD, Gornik HL, Barrett C, et al. 2016 AHA/ACC guideline on the management of patients with lower extremity peripheral artery disease: executive summary: a report of the American College of Cardiology/American Heart Association Task Force on Clinical Practice Guidelines. J Am Coll Cardiol 2017; 69: 1465-508. Erratum in: J Am Coll Cardiol 2017; 69: 1520.

38. Aboyans V, Ricco JB, Bartelink MEL, et al. ESC Scientific Document Group. 2017 ESC Guidelines on the Diagnosis and Treatment of Peripheral Arterial Diseases, in collaboration with the European Society for Vascular Sur- gery (ESVS): Document covering atherosclerotic disease of extracranial carotid and vertebral, mesenteric, renal, upper and lower extremity arteries Endorsed by: the European Stroke Organization (ESO)The Task Force for the Diagnosis and Treatment of Peripheral Arterial Diseases of the European Society of Cardiology (ESC) and of the European Society for Vascular Surgery (ESVS). Eur Heart J 2018; 39: 763-816.

39. Antithrombotic Trialists' Collaboration. Collaborative meta-analysis of randomised trials of antiplatelet therapy for prevention of death, myocardial infarction, and stroke in high risk patients. BMJ 2002; 324: 71-86. Erratum in: BMJ 2002; 324: 141.

40. CAPRIE Steering Committee. A randomised, blinded, trial of clopidogrel versus aspirin in patients at risk of ischaemic events (CAPRIE). CAPRIE Steering Committee. Lancet 1996; 348: 1329-39.

41. Aiello A, Anichini R, Brocco E, et al.; Italian Society of Diabetes; Italian Society of Radiology; Italian Society of Vascular Endovascular Surgery. Treatment of peripheral arterial disease in diabetes: a consensus of the Italian Societies of Diabetes (SID, AMD), Radiology (SIRM) and Vascular Endovascular Surgery (SICVE). Nutr Metab Cardiovasc Dis 2014; 24: 355-69.

42. Anand SS, Bosch J, Eikelboom JW, et al.; COMPASS Investigators. Rivaroxaban with or without aspirin in patients with stable peripheral or carotid artery disease: an international, randomised, double-blind, placebo-controlled trial. Lancet 2018; 391: 219-29.

43. Pratt CM. Analysis of the cilostazol safety database. Am J Cardiol 2001; 87: 28D-33D.

44. Bus SA, Lavery LA, Monteiro-Soares M, et al.; International Working Group on the Diabetic Foot. Guidelines on the prevention of foot ulcers in persons with diabetes (IWGDF 2019 update). Diabetes Metab Res Rev 2020; 36 Suppl 1: e3269.

45. Krishnan S, Nash F, Baker N, Fowler D, Rayman G. Reduc tion in diabetic amputations over 11 years in a defined U.K. population: benefits of multidisciplinary team work and continuous prospective audit. Diabetes Care 2008; 31: 99-101.

46. Jørgensen ME, Almdal TP, Faerch K. Reduced incidence of lower-extremity amputations in a Danish diabetes population from 2000 to 2011. Diabet Med 2014; 31: 443-7.

47. Wang C, Mai L, Yang C, et al. Reducing major lower extremity amputations after the introduction of a multidisciplinary team in patient with diabetes foot ulcer. BMC Endocr Disord 2016; 16: 38.

48. Armstrong DG. The 10-g monofilament: the diagnostic divining rod for the diabetic foot? Diabetes Care 2000, 23: 887.

49. Rayman G, Vas PR, Baker N, et al. The Ipswich Touch Test: a simple and novel method to identify inpatients with diabetes at risk of foot ulceration. Diabetes Care 2011; 34: 1517-8.

50. Fedele D, Comi G, Coscelli C, et al. A multicenter study on the prevalence of diabetic neuropathy in Italy. Italian Diabetic Neuropathy Committee. Diabetes Care 1997; 20: 836-43

51. WHO Working Group. Therapeutic patient education, continuing education programmes for health care providers in the field of chronic diseases. WHO-Europe, Copenhagen, 1998.

52. Assal JP, Mehnert H, Tritschler HJ, Sidorenko A, Keen H; Hellmut Mehnert Award Workshop Participants. On your feet! Workshop on the diabetic foot. J Diabetes Complications 2002; 16: 183-94. 
53. Bus SA, van Netten JJ, Lavery LA, et al.; International Working Group on the Diabetic Foot. IWGDF guidance on the prevention of foot ulcers in at-risk patients with diabetes. Diabetes Metab Res Rev 2016; 32 Suppl 1: 16-24.

54. Hasan R, Firwana B, Elraiyah T, et al. A systematic review and meta-analysis of glycemic control for the prevention of diabetic foot syndrome. J Vasc Surg 2016; 63 (2 Suppl): 22S-28S.e1-2.

55. Trento $M$, Passera P, Tomalino $M$, et al. Therapeutic group education in the follow-up of patient with non insulin treated, non insulin-dependent diabetes mellitus. Diabetes Nutr Metabol 1998; 11: 212-6.

56. Dorresteijn JA, Kriegsman DM, Assendelft WJ, Valk GD. Patient education for preventing diabetic foot ulceration. Cochrane Database Syst Rev 2014; 2014: CD001488.

57. Malone JM, Snyder M, Anderson G, Bernhard VM, Holloway GA Jr, Bunt TJ. Prevention of amputation by diabetic education. Am J Surg 1989; 158: 520-3.

58. Lincoln NB, Radford KA, Game FL, Jeffcoate WJ. Educa tion for secondary prevention of foot ulcers in people with diabetes: a randomised controlled trial. Diabetologia 2008; 51: 1954-61.

59. Van Acker K, Oleen-Burkey M, De Decker L, et al. Cost and resource utilization for prevention and treatment of foot lesions in a diabetic foot clinic in Belgium. Diabetes Res Clin Pract 2000; 50: 87-95.

60. Monami M, Zannoni S, Gaias M, Nreu B, Marchionni N, Mannucci E. Effects of a short educational program for the prevention of foot ulcers in high-risk patients: a randomized controlled trial. Int J Endocrinol 2015; 2015: 615680.

61. Boulton AJ, Gries FA, Jervell JA. Guidelines for the diagnosis and outpatient management of diabetic peripheral neuropathy. Diabet Med 1998; 15: 508-14.

62. Coppola A, Sasso L, Bagnasco A, Giustina A, Gazzaruso $C$. The role of patient education in the prevention and management of type 2 diabetes: an overview. Endocrine 2016; 53: 18-27..

63. Trento M, Passera P, Borgo E, et al. A 5-year randomized controlled study of learning, problem solving ability, and quality of life modifications in people with type 2 diabetes managed by group care. Diabetes Care 2004; 27 : 670-5.

64. Trento M, Gamba S, Gentile L, et al.; ROMEO Investigators. Rethink Organization to iMprove Education and Outcomes (ROMEO): a multicenter randomized trial of lifestyle intervention by group care to manage type 2 diabetes. Diabetes Care 2010; 33: 745-7.

65. Wong CK, Wong WC, Wan YF, Chan AK, Chan FW, Lam CL. Patient Empowerment Programme (PEP) and risk of microvascular diseases among patients with type 2 diabetes in primary care: a population-based propensity-matched cohort study. Diabetes Care 2015; 38: e116-7.

66. Krag $M \varnothing$, Hasselbalch L, Siersma V, et al. The impact of gender on the long-term morbidity and mortality of patients with type 2 diabetes receiving structured personal care: a 13 year follow-up study. Diabetologia 2016; 59: $275-85$

67. Miranda C, Da Ros R. Therapeutic education patient in prevention of diabetic foot: a neglected opportunity. J Diabetes Metab Disord Control 2018; 5: 127-30.

68. van Netten JJ, Lazzarini PA, Armstrong DG, et al. Diabetic Foot Australia guideline on footwear for people with diabetes. J Foot Ankle Res 2018; 11: 2.

69. Bus SA, Waaijman R, Arts $M$, et al. Effect of custom-made footwear on foot ulcer recurrence in diabe- tes: a multicenter randomized controlled trial. Diabetes Care 2013; 36: 4109-16.

70. Ulbrecht JS, Hurley T, Mauger DT, Cavanagh PR. Prevention of recurrent foot ulcers with plantar pressure-based in-shoe orthoses: the CareFUL prevention multicenter randomized controlled trial. Diabetes Care 2014; 37: 1982-9.

71. van Netten JJ, Bril A, van Baal JG. The effect of flexor tenotomy on healing and prevention of neuropathic diabetic foot ulcers on the distal end of the toe. J Foot Ankle Res 2013; 6: 3

72. Rasmussen A, Bjerre-Christensen U, Almdal TP, Holstein P. Percutaneous flexor tenotomy for preventing and treating toe ulcers in people with diabetes mellitus. J Tissue Viability 2013; 22: 68-73.

73. Armstrong DG, Rosales MA, Gashi A. Efficacy of fifth metatarsal head resection for treatment of chronic diabetic foot ulceration. J Am Podiatr Med Assoc 2005; 95: 353-6.

74. Cunha M, Faul J, Steinberg J, Attinger C. Forefoot ulcer recurrence following partial first ray amputation: the role of tendo-achilles lengthening. J Am Podiatr Med Assoc 2010; 100: 80-2.

75. Colen LB, Kim CJ, Grant WP, Yeh JT, Hind B. Achilles tendon lengthening: friend or foe in the diabetic foot? Plast Reconstr Surg 2013; 131: 37e-43e.

76. Faglia E, Clerici G, Caminiti M, Curci V, Somalvico F. Feasibility and effectiveness of internal pedal amputation of phalanx or metatarsal head in diabetic patients with forefoot osteomyelitis. J Foot Ankle Surg 2012; 51: 593-8.

77. Armstrong DG, Holtz-Neiderer K, Wendel C, Mohler MJ, Kimbriel HR, Lavery LA. Skin temperature monitoring reduces the risk for diabetic foot ulceration in high-risk patients. Am J Med 2007; 120: 1042-6.

78. Lavery LA, Higgins KR, Lanctot DR, et al. Home monitoring of foot skin temperatures to prevent ulceration. Diabetes Care 2004; 27: 2642-7.

79. Miranda C, Da Ros R. Prevention of diabetic foot ulcer: a neglected opportunity. Transl Med UniSa 2020; 22: 50-1.

80. Bus SA, van Netten JJ. A shift in priority in diabetic foot care and research: $75 \%$ of foot ulcers are preventable. Diabetes Metab Res Rev 2016; 32 Suppl 1: 195-200.

81. Jeffcoate WJ, Bus SA, Game FL, Hinchliffe RJ, Price PE, Schaper NC; International Working Group on the Diabetic Foot and the European Wound Management Association. Reporting standards of studies and papers on the prevention and management of foot ulcers in diabetes: required details and markers of good quality. Lancet Diabetes Endocrinol 2016; 4: 781-8.

82. van Netten JJ, Woodburn J, Bus SA. The future for diabetic foot ulcer prevention: a paradigm shift from stratified healthcare towards personalized medicine. Diabetes Metab Res Rev 2020; 36 Suppl 1: e3234. 